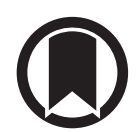

CrossMark

\title{
Air pollution and health: recent advances in air pollution epidemiology to inform the European Green Deal: a joint workshop report of ERS, WHO, ISEE and HEI
}

\author{
Barbara Hoffmann ${ }^{1}$, Nathalie Roebbel ${ }^{2}$, Sophie Gumy ${ }^{2}$, Francesco Forastiere ${ }^{3}$, \\ Bert Brunekreef ${ }^{4}$, Dorota Jarosinska ${ }^{5}$, Katherine D. Walker 6 , \\ Annemoon M. van Erp ${ }^{6}$, Robert O'Keefe ${ }^{6}$, Dan Greenbaum ${ }^{6}$, Martin Williams ${ }^{7,+}$, \\ Michal Krzyzanowski ${ }^{3}$, Frank J. Kelly ${ }^{3}$, Michael Brauer $\odot^{8}$, Hans Bruyninckx ${ }^{9}$ \\ and Hanna Boogaard ${ }^{6}$
}

\begin{abstract}
Affiliations: ${ }^{1}$ Environmental Epidemiology, Institute for Occupational, Social and Environmental Medicine, Medical Faculty, University of Düsseldorf, Dusseldorf, Germany. ${ }^{2}$ Air Quality and Health, Department for Environment, Climate Change and Health, World Health Organization, Geneva, Switzerland. ${ }^{3}$ Environmental Research Group, School of Public Health, Imperial College, London, UK. 'Environmental Epidemiology IRAS, University of Utrecht, Utrecht, The Netherlands. ${ }^{5}$ WHO European Centre for Environment and Health, WHO Regional Office for Europe, Bonn, Germany. ${ }^{6}$ Health Effects Institute, Boston, MA, USA. ${ }^{7}$ MRC-PHE Centre for Environment and Health, Environmental Research Group, School of Public Health, Imperial College, London, UK. ${ }^{8}$ Faculty of Medicine, School of Population and Public Health, University of British Columbia, Institute for Health Metrics and Evaluation, University of Washington, Vancouver, BC, Canada. ${ }^{9}$ European Environment Agency, Copenhagen, Denmark.
\end{abstract}

Correspondence: Barbara Hoffmann, Heinrich Heine University Düsseldorf, Institute for Occupational, Social and Environmental Medicine, AG Umweltepidemiologie POB 101007, Dusseldorf 40225, Germany. E-mail: b. hoffmannduni-duesseldorf.de

\section{@ERSpublications}

Current European air pollution levels, which are in most places well below air quality limit values, still have deleterious health effects. The report discusses ways to move forward with air quality legislation to improve public health. https://bit.ly/3kFRHHf

Cite this article as: Hoffmann B, Roebbel N, Gumy S, et al. Air pollution and health: recent advances in air pollution epidemiology to inform the European Green Deal: a joint workshop report of ERS, WHO, ISEE and HEI. Eur Respir J 2020; 56: 2002575 [https://doi.org/10.1183/13993003.02575-2020].

\section{Introduction}

Ambient air pollutants can adversely affect population health in multiple ways, such as through respiratory, cardiovascular, metabolic, neurological and birth-related outcomes [1-3]. These health effects lead to a substantial burden of disease and economic impact. In response, air quality policies have been put into place across the globe. The European Union has developed an extensive body of legislation which establishes health-based standards for several air pollutants [4-6]. Despite sizable successes of pollution control over the past decades, air pollution-related disease burden among Europeans remains high, leading the European Commission to conclude that the current legislation has only been partially successful in protecting the health of Europeans [7]. Recent evidence from large research programmes and 
comprehensive reviews supports this view and points towards important aspects to consider in striving to reduce air pollution-related burden of disease.

The Health Effects Institute, the European Respiratory Society, the World Health Organization (WHO), and the International Society for Environmental Epidemiology were pleased to organise a joint meeting in Brussels, Belgium, on 21-22 January 2020. The event was also supported by the European Commission. The aim of the meeting was to review the latest science on major pollutants, focusing on particulate matter $2.5 \mu \mathrm{m}$ or less in diameter $\left(\mathrm{PM}_{2.5}\right)$ and nitrogen dioxide, to help evaluate the need for updating Europe's air quality policies and in support of the European Green Deal. A number of important scientific and policy questions about the causal links between air pollution and health, its effects at low levels of exposure, the relative contributions of different sources or constituents, and ultimately the question of how to achieve the most health benefits most cost-effectively were presented and discussed. This workshop report summarises the key findings of the meeting.

\section{European Air Quality Regulation}

The Fitness Check has found that EU regulations have contributed to improved air quality, but substantial health burden remains.

The EU has the overarching goal to protect European citizens and susceptible subpopulations from the adverse effects of major ambient air pollutants by both regulating emissions of air pollutants at the source (i.e. National Emission Ceilings Directive and source-specific standards), and by monitoring and limiting population exposure according to a harmonised monitoring scheme throughout the European Union (Ambient Air Quality Directive). In 2019, the European Commission conducted a retrospective analysis of whether these EU air quality actions are actually fit for this purpose (i.e. the "fitness check" [7]). It concluded that the actions have been partially successful by contributing to a downward trend in air pollution, but that air pollution remains a major health and environmental concern, leading to more than 400000 premature deaths [8] and total health-related external costs in the range of EUR 330-940 billion per year [9]. Moreover, the Commission noted that the current air quality standards are less ambitious than scientific health-based guidelines from the WHO and those of non-European high income countries and has proposed revising the air quality standards to bring them into closer alignment with WHO guidelines $[7,10]$.

The European Green Deal is a comprehensive road map striving to make the EU more resource-efficient and sustainable, which was brought forward by the European Commission in 2019 [11]. The Green Deal has the overarching aim of reducing sources of carbon dioxide sufficiently to make Europe climate neutral by 2050. It also aims for a zero emission strategy of air pollutants and foresees a revision of the European Air Quality Directive in the current legislative period [12]. The European Green Deal coincides with the United Nations' Sustainable Development Goals call for major reductions in exposure to air pollution by 2030 [13]. Now, it also plays an important role in the climate-friendly rebuilding of the European economy after the coronavirus disease 2019 (COVID-19) pandemic.

\section{Recent reviews regarding the health effects of ambient air pollution: what do they tell us? \\ EU regulations need to be updated to reflect the latest scientific evidence on air pollution and health.}

Regular synthesis of the scientific evidence to assess the strength of causal relationships between air pollution and health are crucial steps for policy makers. This process relies on interdisciplinary teams of scientists to assess potential biases, limitations and strengths of the individual epidemiological, experimental and mechanistic studies and ultimately develops an integrated assessment about causality and characteristics of the exposure-response-relationship.

While the US Environmental Protection Agency is mandated by law to conduct such comprehensive reviews on individual pollutants on a regular basis, Europe relies on the WHO Air Quality Guidelines development process for the rigorous evaluation of the scientific evidence and guidelines to protect public health across European countries. However, since the European Union Air Quality Directive was published in 2008, a sizable gap exists between the EU limit value for annual average $\mathrm{PM}_{2.5}$ concentration of $25 \mu \mathrm{g} \cdot \mathrm{m}^{-3}$ and the WHO health-based guideline of $10 \mu \mathrm{g} \cdot \mathrm{m}^{-3}$ established in 2005 [10]. In addition, a large body of evidence has accumulated specifically for $\mathrm{PM}_{2.5}$ since the last revision of the WHO Air Quality Guidelines in 2005. As a consequence of this strengthened evidence, in 2012, the US National Ambient Air Quality Standard for $\mathrm{PM}_{2.5}$ was reduced from 15 to $12 \mu \mathrm{g} \cdot \mathrm{m}^{-3}$. Other countries' air quality standards are also in better alignment with WHO Air Quality Guidelines [14] than the EU limit values. Currently, WHO is updating the global Air Quality Guidelines to better reflect recent evidence [15]. The updated 
WHO global Air Quality Guidelines, expected to be ready in early 2021, will provide important input for the Commission's ambition to align legal standards of $\mathrm{PM}_{2.5}$ with health-based recommendations.

The workshop also reviewed recent evidence on $\mathrm{NO}_{2}$, which plays a central role in European air pollution policy, as traffic-related emissions have remained high and many member states have violated long-term limit values for $\mathrm{NO}_{2}$ concentrations. While $\mathrm{NO}_{2}$ has been less studied than $\mathrm{PM}_{2.5}$, evidence for an independent effect of $\mathrm{NO}_{2}$ on mortality and potentially on the development of asthma in children is growing $[16,17]$. Nonetheless, there is more certainty about the health benefits of interventions that reduce both $\mathrm{PM}_{2.5}$ and $\mathrm{NO}_{2}$ than those that target $\mathrm{NO}_{2}$ alone [16].

Growing concern has been raised regarding ultrafine particles (UFP), because of their potential for travelling deeper into the lungs, into the bloodstream and into the brain. Because exposures to UFPs vary highly in space and time and co-occur with other pollutants, assessment of their independent health effects has been difficult. Despite these challenges, recent reviews conclude that the evidence, from studies of short-term exposures particularly, suggests that UFPs contribute to respiratory, cardiovascular and nervous system health effects [18-21]. More definitive conclusions have been limited by lack of comprehensive monitoring and studies on effects of long-term exposures, so this area will need to be re-evaluated as new evidence becomes available. Nevertheless, while specific guidelines cannot be recommended yet, the available evidence supports the need for reductions in UFP emissions and human exposure.

\section{How low should we go? New health research on low-level ambient air pollution} New studies have reported strong associations of health effects with air pollution at levels below current standards, with no observable thresholds.

Air pollution levels and the air pollution-attributable burden of disease are declining in most European countries. Nonetheless, new studies report strong associations with health effects at levels below current legal standards in the general population, with no observable thresholds [22, 23]. Two of the largest new studies undertaken to examine adverse health effects of low levels of ambient air pollution in USA and Canada were published recently by the Health Effects Institute $[24,25]$. Results from the third study in the HEI programme, focused on Europe, are expected later this year [26]. Each study uses state-of-the-art exposure assessment methods and very large populations, and put special emphasis on clarifying the exposure-response relationship at low levels of exposure.

Di et al. [27] used Medicare insurance data for 61 million Americans, aged 65 years and older and enrolled between 2000 and 2012. By combining air monitoring, satellite, atmospheric transport models and land use regression models, the investigators developed hybrid models for the continental USA to estimate $\mathrm{PM}_{2.5}$ at $1 \mathrm{~km} \times 1 \mathrm{~km}$ grids. BrAUER et al. [24] used a cohort of approximately 9 million Canadians, based on census and health survey data. They combined satellite data, ground-level measurements, atmospheric modelling data, and land-use covariates to estimate $\mathrm{PM}_{2.5}$ exposures at a fine resolution across North America from 1981 to 2016. BRUNEKREEF et al. [26] used pooled data from the well-characterized ESCAPE cohorts (European Study of Cohorts for Air Pollution Effects) and large administrative cohorts resulting in a study population of about 35 million persons across Europe. They developed hybrid Europe-wide exposure models that utilise land use information, dispersion modelling, satellite data, and monitoring data for $\mathrm{PM}_{2.5}$ and other pollutants to estimate long-term pollutant concentrations at residential address for the cohort members.

All three studies report associations between mortality and $\mathrm{PM}_{2.5}$ concentrations at levels as low as $5 \mu \mathrm{g} \cdot \mathrm{m}^{-3}$, well below the current EU limit values, the US National Ambient Air Quality Standards and even below the 2005 WHO air quality guideline value of $10 \mu \mathrm{g} \cdot \mathrm{m}^{-3}$. The European study also investigated traffic-related exposures to $\mathrm{NO}_{2}$ and black carbon and found robust associations of the exposure with mortality and incidence of cardiovascular and respiratory disease also for these pollutants. The associations were very stable in multi-exposure models and were observed well below the European annual limit value of $40 \mu \mathrm{g} \cdot \mathrm{m}^{-3}$ for $\mathrm{NO}_{2}$ and even below the WHO recommended value for health impact assessment of $20 \mu \mathrm{g} \cdot \mathrm{m}^{-3}$. For both $\mathrm{PM}_{2.5}$ and $\mathrm{NO}_{2}$, associations tended to have steeper slopes at low exposures with no indication of a threshold.

The lack of a threshold together with robust associations at low levels of air pollution underscores the large potential for health benefits by lowering the average exposure of the population, even though most of the population in the USA, Canada and Europe are currently exposed to levels below the respective legal limit values and standards. For example in the EU, while only $8 \%$ of the urban population was exposed to concentrations exceeding the annual EU limit value of $25 \mu \mathrm{g} \cdot \mathrm{m}^{-3}$ in 2017 [28], 77\% exceeded the annual WHO air quality guideline for $\mathrm{PM}_{2.5}$ of $10 \mu \mathrm{g} \cdot \mathrm{m}^{-3}$. 
Implications for future health impact assessment and regulation

Burden of disease calculations, health impact assessment, and accountability studies are powerful tools to shape policy. Abatement measures see significant success.

Various burden assessments, including from the European Environment Agency, WHO and the Global Burden of Disease consortium, have played a key role in identifying the overall and relative importance of air pollution compared to other risk factors, showing that ambient air pollution is currently ranked fifth among the leading risk factors for mortality in the EU [7, 29, 30].

Using burden of disease and health impact assessment approaches, the outcome of various policy options for different scenarios can be predicted. The outcomes can be expressed both in terms of number of deaths or illnesses avoided, or in economic terms, by putting monetary value on health outcomes. Studies show that the estimated health benefits outweigh by far the implementation costs of air quality actions [9, 31]. More specifically, a recent evaluation of various policy options for air pollution standards concluded that an approach aiming for the reduction of average long-term exposures of the European population would have a better cost-benefit ratio than a strategy aimed only at reducing peak exposures with fixed limit values [32]. Likewise, even though current evidence does not clearly identify differences in the toxicity of $\mathrm{PM}_{2.5}$ from different sources [33,34], cost-benefit analyses allow for identification of the most cost-effective targets of emission reduction measures from various sources. It is also important to calculate the co-benefits of air quality improvements associated with specific climate change actions as they are inexorably linked, as demonstrated, for example, by the benefits of reducing coal extraction and combustion [35]. An integrated approach to climate change and air pollution can therefore lead to significant co-benefits, as well as to reducing the risk of introducing climate change measures with significant negative impacts on air quality [36-38].

To date, such assessments have not been extensively validated by comparison with results of "real world" studies of regulatory programmes and interventions using actual health outcome data. Accountability studies designed to assess whether such actions lead to the expected health benefits have emerged to fulfil that role [39]. In some cases, such studies have provided evidence for the benefits of specific actions and policies, but in other cases their evidence has been weaker than had been originally anticipated. Some of the first, and classic, examples of accountability studies are those documenting air quality and health improvements associated with temporary factory closures of a steel mill and copper smelters in the USA $[40,41]$. Another early well-known example is the study in Dublin, Ireland, which reported substantial air quality improvements and decreases in respiratory mortality after the introduction of a city-wide ban on the sale of coal $[42,43]$. The experience from these accountability studies has been recently reviewed and recommendations have been offered for the design and conduct of future studies [44-47]. A review of practical interventions to reduce outdoor air pollution at the local level was recently published [48], though it remains clear that air quality actions are needed at all levels (international, national, local) and across all sectors (e.g. transport, energy, agriculture) to bring significant health benefits [49].

The evidence base highlights the challenges related to establishing the effectiveness of specific air pollution interventions on outcomes. It also points to the need for improved study design and analysis methods, including use of causal inference approaches [50-52]. Though challenging, intervention studies are appealing and are the closest epidemiological equivalent to controlled experimental studies, thereby contributing to the causality debate. The prospective planning of evaluations and an evaluation component built into the design and implementation of large interventions may be particularly beneficial.

\section{Air pollution research priorities and policy implications}

Despite the remarkable growth in knowledge about air pollution and health, a range of issues warrant additional research. As governments act to reduce air pollution, there is a continuing need for research to shed more light on disease risk at very low levels of air pollution, identify the air pollution sources and pollutants most responsible for disease burden, identify subgroups of the population at most risk, and assess the public health effectiveness of actions taken to improve air quality. Specifically for vulnerable subpopulations, better communication of the risks of air pollution, advising on how to reduce exposure at the community (local) level and to reduce individual health risks, and involvement of healthcare professionals in providing this information need to be strengthened; with several activities being under way [53-55].

Despite existing research needs, the strength of the evidence is overwhelming and provides a sufficient basis for policy decisions. Growing scientific evidence for effects at levels below current air quality standards and the large overall estimates of the air pollution-attributable burden of disease, as well as the need to reduce greenhouse gases, imply that more stringent air quality standards and guidelines should be considered in the future to improve public health even further. To maximise health benefits, it is 
important to implement measures that will reduce peak exposures in specific hotspots, the average exposure of all EU citizens, and inequalities in air pollution risk. To tackle the health effects of air pollution, bold, readily available, and cost-effective air quality actions are needed at all levels (international, national, local) and across all sectors (e.g. transport, energy, agriculture). The estimated health benefits outweigh by far the implementation costs of air quality actions. Co-benefits in other policy areas such as climate change and urban structure need to be considered as well.

The current COVID-19 pandemic has profoundly impacted the world, and air pollution may increase susceptibility to mortality and morbidity from COVID-19 [56, 57]. The European Green deal must be central to a resilient and healthy recovery from the COVID-19 pandemic. Such efforts must be further amplified and multiplied in countries across the globe, including the USA, to limit global warming and improve air quality for the sake of planetary and human health. Green and healthy recovery from COVID-19 is also at heart of a WHO Manifesto [58], with strong emphasis on reducing pollution, protecting nature, promoting healthy energy transition, sustainable food systems and healthy and liveable cities.

A coordinated and systemic approach, which also takes equity issues into account, will be needed to make Europe the first climate-neutral and zero-emission continent by 2050. The European Green Deal and the Commission's pollution action plan for air, water and soil, to be adopted by 2021, can provide a unique opportunity to operationalise the fundamental changes that are necessary and build upon the synergies between air quality and climate actions.

We dedicate this to the memory of Kirk R. Smith, Professor at the University of California, Berkeley, who never ceased to raise his voice for the poor and the planet, and to Professor Martin Williams, Imperial College London, who has been a leader of research and policy development to solve the problems of poor air quality in the UK and more widely in Europe throughout the past four decades.

Conflict of interest: B. Hoffmann has nothing to disclose. N. Roebbel has nothing to disclose. S. Gumy has nothing to disclose. F. Forastiere has nothing to disclose. B. Brunekreef has nothing to disclose. D. Jarosinska has nothing to disclose. K.D. Walker reports core funding for the Health Effects Institute from the USEPA and from the motor vehicle industry. A.M. van Erp reports that the Health Effects Institute receives funding from the United States Environmental Protection Agency and the motor vehicle industry; the contents of this document have not been reviewed by institutions that support the Health Effects Institute and no endorsement by them should be inferred. R. O'Keefe has nothing to disclose. D. Greenbaum has nothing to disclose. M. Williams has nothing to disclose. M. Krzyzanowski has nothing to disclose. F.J. Kelly has nothing to disclose. M. Brauer reports grants from Health Effects Institute, during the conduct of the study. H. Bruyninckx has nothing to disclose. H. Boogaard has nothing to disclose.

\section{References}

1 World Health Organization, Regional Office for Europe. Review of Evidence on Health Aspects of Air Pollution, REVIHAAP Project: Technical Report, 2013. Copenhagen, WHO Regional Office for Europe, 2013.

2 Thurston GD, Kipen H, Annesi-Maesano I, et al. A joint ERS/ATS policy statement: what constitutes an adverse health effect of air pollution? An analytical framework. Eur Respir J 2017; 49: 1600419.

3 Schraufnagel DE, Balmes JR, Cowl CT, et al. Air pollution and non-communicable diseases: a review by the Forum of International Respiratory Societies' environmental committee, part 1: the damaging effects of air pollution. Chest 2019; 155: 409-416.

4 European Commission. Directive 2008/50/EC of the European Parliament and of the Council of 21 May 2008 on ambient air quality and cleaner air for Europe, OJ L 152, 11.6.2008.

5 European Commission. Directive (EU) 2016/2284 of the European Parliament and of the Council of 14 December 2016 on the reduction of national emissions of certain atmospheric pollutants, amending Directive 2003/35/EC and repealing Directive 2001/81/EC (Text with EEA relevance), OJ L 344, 17.12.2016.

6 European Commission. Directive 2010/75/EU of the European Parliament and of the Council of 24 November 2010 on industrial emissions (integrated pollution prevention and control) Text with EEA relevance, OJ L 334, 17.12.2010.

7 European Commission. Fitness check of the Ambient Air Quality Directives. Directive 2004/107/EC relating to arsenic, cadmium, mercury, nickel and polycyclic aromatic hydrocarbons in ambient air and Directive 2008/50/EC on ambient air quality and cleaner air for Europe. SWD (2019) 427 final. Brussels, 28.11.2019. Commission Staff Working Document.

8 European Environment Agency. Air Quality in Europe, 2019 Report. Luxembourg, Publications Office of the European Union, 2019.

9 European Commission. Impact Assessment. SWD (2013) 531 final. Brussels, 18.12.2013. Commission Staff Working Document.

10 World Health Organization. Air Quality Guidelines Global Update 2005, Particulate Matter, Ozone, Nitrogen Dioxide and Sulfur Dioxide. Copenhagen, WHO Regional Office for Europe, 2006.

11 European Commission. Communication from the Commission to the European Parliament, the European Council, the Council, the European Economic and Social Commitee and the Commitee of the Regions, The European Green Deal. COM (2019) 640 final. Brussels, 11.12.2019.

12 Haines A, Scheelbeek P. European Green Deal: a major opportunity for health improvement. Lancet 2020; 395: $1327-1329$. 
13 United Nations (UN). About the Sustainable Development Goals. www.un.org/sustainabledevelopment/ sustainable-development-goals/. Date last updated: 26 May 2020. Date last accessed: 26 May 2020.

14 Joss MK, Eeftens M, Gintowt E, et al. Time to harmonize national ambient air quality standards. Int $J$ Public Health 2017; 62: 453-462.

15 Chen J, Hoek G. Long-term exposure to PM and all-cause and cause-specific mortality: A systematic review and meta-analysis. Environ Int 2020; in press https://doi.org/10.1016/j.envint.2020.105974.

16 Committee on the Medical Effects of Air Pollutants (COMEAP). Associations of Long-term Average Concentrations of Nitrogen Dioxide with Mortality. London, Public Health England, 2018.

17 Achakulwisut P, Brauer M, Hystad P, et al. Global, national, and urban burdens of paediatric asthma incidence attributable to ambient NO2 pollution: estimates from global datasets. Lancet Planet Health 2019; 3 : e166-e178.

18 US Environmental Protection Agency. Integrated Science Assessment (ISA) for Particulate Matter. Washington, US Environmental Protection Agency, 2019.

19 Morawska L, Wierzbicka A, Buonanno G, et al. Ambient Ultrafine Particles: Evidence for Policy Makers. A Report Prepared by the 'Thinking Outside The Box' Team. Available from: https://efca.net/files/WHITE\%20PAPER-UFP\% 20evidence $\% 20$ for\%20policy\%20makers\%20(25\%20OCT).pdf

20 HEI Review Panel on Ultrafine Particles. Understanding the Health Effects of Ambient Ultrafine Particles. HEI Perspectives 3. Boston, Health Effects Institute, 2013.

21 Ohlwein S, Kappeler R, Joss MK, et al. Health effects of ultrafine particles: a systematic literature review update of epidemiological evidence. Int J Public Health 2019; 64: 547-559.

22 Papadogeorgou G, Kioumourtzoglou M-A, Braun D, et al. Low levels of air pollution and health: effect estimates, methodological challenges, and future directions. Curr Envir Health Rpt 2019; 6: 105-115.

23 Pope CA, Coleman N, Pond ZA, et al. Fine particulate air pollution and human mortality: 25+ years of cohort studies. Environ Res 2020; 183: 108924.

24 Brauer M, Brook JR, Christidis T, et al. Mortality-Air Pollution Associations in Low-Exposure Environments (MAPLE): phase 1. Res Rep Health Eff Inst 2019; 203: 1-87.

25 Dominici F, Schwartz J, Di Q, et al. Assessing adverse health effects of long-term exposure to low levels of ambient air pollution: phase 1. Res Rep Health Eff Inst 2019; 200: 1-51.

26 Brunekreef B, Strak M, Chen J, et al. Mortality and Morbidity Effects of Long-Term Exposure To Low-Level PM2.5, Black Carbon, $\mathrm{NO}_{2}$ and $\mathrm{O}_{3}$ : An Analysis of European Cohorts - ELAPSE project: Effects of Low-Level Air Pollution. HEI Research Report 2020; submitted. www.healtheffects.org/research/ongoing-research/mortality-andmorbidity-effects-long-term-exposure-low-level-pm25-black

27 Di Q, Wang Y, Zanobetti A, et al. Air pollution and mortality in the medicare population. $N$ Engl J Med 2017; 376: 2513-2522.

28 European Environment Agency. Exceedance of Air Quality Standards in Urban Areas. www.eea.europa.eu/ data-and-maps/indicators/exceedance-of-air-quality-limit-3. Last updated: 2019. Date last accessed: 26 May 2020.

29 GBD 2017 Risk Factor Collaborators, Bisanzio D, Shokraneh F. Global, regional, and national comparative risk assessment of 84 behavioural, environmental and occupational, and metabolic risks or clusters of risks for 195 countries and territories, 1990-2017: a systematic analysis for the Global Burden of Disease Study 2017. Lancet 2018; 392: P1923-P1994.

30 World Health Organization. Ambient Air Pollution: a Global Assessment of Exposure and Burden of Disease. Geneva, World Health Organization, 2016.

31 US Environmental Protection Agency. The Benefits and Costs of the Clean Air Act from 1990 to 2020. Washington, US Environmental Protection Agency, 2011.

32 Amann M, Bertok I, Cabala R, et al. Target Setting Approaches for Cost-effective Reductions of Population Exposure to Fine Particulate Matter in Europe, Background paper for the meeting of the CAFE Working Group on Target Setting and Policy Advice. CAFE Scenario Analysis Report: 4. Laxenburg, International Institute for Applied Systems Analysis, 2005.

33 Stanek LW, Sacks JD, Dutton SJ, et al. Attributing health effects to apportioned components and sources of particulate matter: an evaluation of collective results. Atmos Environ 2011; 45: 5655-5663.

34 Lippmann M, Chen L-C, Gordon T, et al. National Particle Component Toxicity (NPACT) Initiative: integrated epidemiologic and toxicologic studies of the health effects of particulate matter components. Res Rep Health Eff Inst 2013; 177: 5-13.

35 Thurston GD, Matteis SD, Murray K, et al. Maximizing the public health benefits from climate action. Environ Sci Technol 2018; 52: 3852-3853.

36 von Schneidemesser E, Monks PS. Air quality and climate - synergies and trade-offs. Environ Sci: Processes Impacts 2013; 15: 1315-1325.

37 Williams M. Tackling climate change: what is the impact on air pollution? Carbon Manage 2012; 3: 511-519.

38 Amann M, Heyes C, Kiesewetter G, et al. Air Quality, Complementary Impact Assessment on Interactions between EU Air Quality Policy and Climate and Energy Policy. Brussels, European Parliament, 2014.

39 van Erp AM, Kelly FJ, Demerjian KL, et al. Progress in research to assess the effectiveness of air quality interventions towards improving public health. Air Qual Atmos Health 2012; 5: 217-230.

40 Pope CA. Respiratory disease associated with community air pollution and a steel mill, Utah Valley. Am J Public Health 1989; 79: 623-628.

41 Pope CA, Rodermund DL, Gee MM. Mortality effects of a copper smelter strike and reduced ambient sulfate particulate matter air pollution. Environ Health Perspect 2007; 115: 679-683.

42 Clancy L, Goodman P, Sinclair H, et al. Effect of air-pollution control on death rates in Dublin, Ireland: an intervention study. Lancet 2002; 360: 1210-1214.

43 Dockery DW, Rich DQ, Goodman PG, et al. Effect of air pollution control on mortality and hospital admissions in Ireland. Res Rep Health Eff Inst 2013; 176: 3-109.

44 Burns J, Boogaard H, Polus S, et al. Interventions to reduce ambient particulate matter air pollution and their effect on health. Cochrane Database Syst Rev 2019; 5: CD010919.

45 Boogaard $\mathrm{H}$, van Erp AM, Walker $\mathrm{KD}$, et al. Accountability studies on air pollution and health: the HEI experience. Curr Envir Health Rep 2017; 4: 514-522. 
Rich DQ. Accountability studies of air pollution and health effects: lessons learned and recommendations for future natural experiment opportunities. Environ Int 2017; 100: 62-78.

47 Schraufnagel DE, Balmes JR, Matteis SD, et al. Health benefits of air pollution reduction. Ann Am Thorac Soc 2019; 16: 1478-1487.

48 Public Health England. Review of Interventions to Improve Outdoor Air Quality and Public Health. London, Public Health England, 2019.

49 Maas R. Towards Cleaner Air, Scientific Assessment Report 2016: Summary for Policymakers. Oslo, MEP Steering Body and Working Group on Effects of the Convention on Long-Range Transboundary Air Pollution, 2016.

50 Carone M, Dominici F, Sheppard L. In pursuit of evidence in air pollution epidemiology: the role of causally driven data science. Epidemiology 2020; 31: 1-6.

51 Russell ATG, Tolbert P, Henneman LRF, et al. Impacts of regulations on air quality and emergency department visits in the Atlanta metropolitan area, 1999-2013. Res Rep Health Eff Inst 2018; 195: 1-93.

52 Zigler CM, Choirat C, Dominici F. Impact of National Ambient Air Quality Standards nonattainment designations on particulate pollution and health. Epidemiology 2018; 29: 165-174.

53 Carlsten C, Salvi S, Wong GWK, et al. Personal strategies to minimise effects of air pollution on respiratory health: advice for providers, patients and the public. Eur Respir J 2020; 55: 1902056.

54 World Health Organization. Personal Interventions and Risk Communication on Air Pollution. www.who.int/ news-room/q-a-detail/personal-interventions-and-risk-communication-on-air-pollution Date last updated: 7 Aug 2020. Date last accessed: 7 Aug 2020.

55 World Health Organization. Synthesizing Evidence and Knowledge on Air Pollution. www.who.int/activities/ synthesizing-evidence-and-knowledge-on-air-pollution Date last updated: 7 Aug 2020. Date last accessed: 7 Aug 2020.

56 Heederik DJJ, Smit LAM, Vermeulen RCH. Go slow to go fast: a plea for sustained scientific rigour in air pollution research during the COVID-19 pandemic. Eur Respir J 2020; 56: 2001361.

57 Villeneuve PJ, Goldberg MS. Methodological Considerations for Epidemiological Studies of Air Pollution and the SARS and COVID-19 Coronavirus Outbreaks. Environ Health Perspect 2020; 128: 95001.

58 World Health Organization. WHO Manifesto for a Healthy Recovery from COVID-19. Geneva, World Health Organization, 2020. 